Esta obra está bajo una Licencia Creative Commons Atribución-NoComercial-Compartirlgual 4.0 Internacional

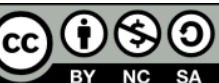

Entre la diversidad y el estereotipo: representaciones juveniles en dos documentales argentinos recientes

Alfredo Dillon

DOI: https://doi.org/10.24215/16696581e245

\title{
Entre la diversidad y el estereotipo: representaciones juveniles en dos documentales argentinos recientes
}

\section{Between Diversity and Stereotype: \\ youth representations in two recent Argentine documentaries}

\author{
Alfredo Dillon alfredodillon@yahoo.com \\ https://orcid.org/0000-0001-7571-6693
}

Instituto de Investigaciones; Facultad de Ciencias Sociales; Universidad Católica Argentina Argentina

\section{Resumen}

El objetivo de este trabajo es analizar las representaciones de los adolescentes en dos documentales argentinos recientes sobre educación: La educación prohibida (2012), dirigido Question, Vol. 1, N. ${ }^{\circ}$ 65, abril 2020. ISSN 1669-6581

Instituto de Investigaciones en Comunicación | Facultad de Periodismo y Comunicación Social | Universidad Nacional de La Plata 
Alfredo Dillon Entre la diversidad y el estereotipo: representaciones juveniles en dos documentales argentinos recientes

por Germán Doin, y Después de Sarmiento (2015), dirigido por Francisco Márquez. En ambas películas los jóvenes son presentados en el contexto de un posicionamiento con respecto a los procesos educativos y la institución escolar. En ambas, la problematización de la institución escolar resulta inseparable de la reflexión sobre las características, necesidades y deseos de los adolescentes actuales, quienes constituyen el centro del proceso educativo. El artículo explora, por medio de un análisis formal de las películas, cómo en cada obra los procedimientos estéticos y narrativos se traducen en representaciones juveniles muy distintas entre sí. Si bien cada documental tiene objetivos diversos -el primero asume una modalidad "activista"; el segundo se plantea como un documental etnográfico-, las diferencias entre ambos van más allá del nivel de la enunciación. Entre otras cuestiones, la construcción un adolescente esencial en La educación prohibida invisibiliza las desigualdades sociales que Después de Sarmiento pone en evidencia.

Palabras Clave: representaciones; juventud; cine argentino; documental; estudios sobre cine.

\section{Abstract}

The objective of this article is to analyze the representations of adolescents in two recent Argentine documentaries on education: La educación prohibida (2012), directed by Germán Doin, and Después de Sarmiento (2015), directed by Francisco Márquez. In both films, young people are presented in the context of a position regarding educational processes and the school institution. In both, the problematization of the school institution is inseparable from the reflection on the characteristics, needs and desires of the current adolescents. The article explores, through a formal analysis of the films, how in each work the aesthetic and narrative procedures translate into very different youth representations. Although each documentary has different objectives -the first one assumes an "activist" modality; the second is presented as an ethnographic documentary-, the differences between the two go beyond the level of the enunciation. Among other issues, the construction of an "essential" adolescent in La educación prohibida makes invisible the social inequalities that Después de Sarmiento demonstrates.

Keywords: representations; youth; argentine cinema; documentary; film studies. 
Alfredo Dillon Entre la diversidad y el estereotipo: representaciones juveniles en dos documentales argentinos recientes

\section{Introducción}

Los estudios sobre representaciones mediáticas de los jóvenes argentinos suelen encontrar ciertos tópicos recurrentes, por ejemplo en relación con la abulia y la falta de pretensiones (en los jóvenes de clase media), o la violencia y la marginalidad (en el caso de los jóvenes pobres), que han sido señalados de manera frecuente en la televisión, pero también en el cine reciente (Sebastián Meschengieser y Federico Lisica, 2004; Miriam Goldstein, 2008). Otros ejes frecuentes de indagación en el terreno de las representaciones cinematográficas sobre los jóvenes han sido las relaciones intergeneracionales entre estos y sus padres (Eduardo Cartoccio, 2010), así como la construcción de la figura juvenil como índice de los procesos políticos que atraviesa el país (Andrés Farhi, 2005). La mayoría de los trabajos se han centrado en corpus ficcionales, dejando de lado el análisis de las representaciones juveniles en la producción documental.

La propuesta de este artículo es pensar qué dicen -qué muestran- los documentales argentinos La educación prohibida (2012) y Después de Sarmiento (2015) acerca de los adolescentes, teniendo en cuenta que la temática que comparten -la educación- involucra necesariamente una determinada concepción de lo juvenil. El estudio y el paso por la escuela forman parte de la trayectoria generalmente esperada para los adolescentes en Argentina, en particular luego de la sanción de la Ley de Educación Nacional en 2006, que estableció la obligatoriedad del nivel medio. En este sentido, la escuela se inscribe en la moratoria psicosocial conceptualizada por Erik Erikson (1980) para definir la adolescencia: según esta noción, esta etapa constituye una suerte de período preparatorio o de prueba en que el adolescente puede experimentar con diferentes roles y creencias, puede probar diferentes experiencias en la búsqueda de su identidad, sin mayores responsabilidades. ${ }^{1}$

Abordar a los adolescentes en la escuela implica presentarlos en el marco de su proceso de socialización; la cultura juvenil se manifiesta allí bajo los condicionamientos que impone la institución educativa. De todos modos, buena parte de la sociología hoy pone el foco en las dificultades que impiden que ese proceso socializador sea exitoso: Alain Touraine (2006)

${ }^{1}$ El concepto de moratoria social ha sido muy criticado. Por ejemplo, para Reguillo (2012, p. 132) esta categoría responde a un pensamiento eurocéntrico que «asume que todos los jóvenes ingresan, por su condición, a un espacio de privilegios y excepciones que los autorizan a vivir al margen de las responsabilidades, compromisos y angustias del mundo adulto». También David Buckingham critica los planteos de este autor: "Erikson and his followers claim that the stages they identify are universal, although it could be argued that 'adolescence' as such does not exist in earlier historical periods, or in other cultures» (2008, p. 3).

Question, Vol. 1, N. ${ }^{\circ}$ 65, abril 2020. ISSN 1669-6581

Instituto de Investigaciones en Comunicación | Facultad de Periodismo y Comunicación Social | Universidad Nacional de La Plata La Plata | Buenos Aires | Argentina

Página 3 de 16 
Alfredo Dillon Entre la diversidad y el estereotipo: representaciones juveniles en dos documentales argentinos recientes

advierte sobre la tendencia contemporánea la desocialización, que implica la desaparición de los roles, normas y valores sociales mediante los que se construía el mundo vivido en la modernidad. Esto supone que las instituciones de socialización -entre ellas, la escuela y la familia- perdieron su capacidad de producir sujetos $y$, por lo tanto, ven progresivamente debilitado su poder de regulación de las conductas. En el marco de esa crisis del formato escolar, que se registra de manera especialmente aguda en la secundaria, nos interesa indagar qué mirada sobre los jóvenes (y sobre la educación) se desprende de los documentales que eligen contar la escuela.

\section{Modo de abordaje}

Este trabajo se basa, de manera central, en un análisis inmanente de las películas seleccionadas, con particular atención a las representaciones de los jóvenes en una doble dimensión: cómo se los ve y se los escucha (en el espacio fílmico), y qué dicen sobre ellos otras voces (adultas) presentes en cada documental. Aunque la perspectiva temática resultó crucial para la definición del corpus, se procuró evitar un análisis meramente contenidista, para reparar en los procedimientos y las estructuras narrativas por medio de los cuales las películas representan a los jóvenes.

Nos enfocamos especialmente en los personajes jóvenes, utilizando aquí la categoría personaje en un sentido amplio, no exclusivo de las narrativas ficcionales, aunque uno de los documentales (La educación prohibida) tiene la particularidad de apelar al procedimiento de la ficcionalización. También se presta atención al género seleccionado en cada caso, y al diálogo entre ese formato y el contenido del documental. En otras palabras, asumimos que en ningún caso un documental es mímesis transparente de la realidad, sino una construcción discursiva que pone en juego muchos de los procedimientos habituales en el discurso ficcional. La diferencia entre documental y ficción no radica, por lo tanto, en las operaciones retóricas de representación, sino en el pacto de lectura ${ }^{2}$ que cada discurso propone, asociado con un determinado destinatario modelo. ${ }^{3}$

\footnotetext{
${ }^{2}$ Carl Plantinga (2011, s/p) afirma que «un documental se propone ser considerado verídico; [...] es diseñado para ser tomado como una guía confiable hacia los elementos relevantes de la escena profílmica».

${ }^{3}$ En este sentido es interesante la propuesta de Michael Chanan (2007), quien distingue al documental de la ficción a partir del modo como cada uno se dirige al receptor: la película de ficción sería heredera de la novela y del arte dramático, y por lo tanto se dirige al espectador como individuo privado, es decir, a su subjetividad y a su vida sentimental. El documental, en cambio, le «habla al espectador como ciudadano, como un miembro de un colectivo social, como un participante de la esfera pública» (p. 16).

Question, Vol. 1, N. ${ }^{\circ} 65$, abril 2020. ISSN 1669-6581

Instituto de Investigaciones en Comunicación | Facultad de Periodismo y Comunicación Social | Universidad Nacional de La Plata 
Alfredo Dillon Entre la diversidad y el estereotipo: representaciones juveniles en dos documentales argentinos recientes

Finalmente, para indagar en las condiciones de producción de cada película -indisociables, en el cine, de la estética de la obra- se decidió entrevistar a los directores de cada documental. La palabra de ellos no fue considerada como una autoridad que estableciera la interpretación correcta de cada película, sino que se los consultó para poder contextualizar dos documentales que plantean estéticas, mecanismos de producción y modos de circulación radicalmente diferentes. En este sentido, el artículo indaga sobre las representaciones juveniles pero también sobre las diversas posibilidades de funcionamiento del documental contemporáneo en Argentina.

\section{Presentación del corpus}

La educación prohibida y Después de Sarmiento comparten un tema: la educación. En la última década, en el contexto de la consolidación y el crecimiento sostenido de la industria cinematográfica argentina, el subgénero documental sobre educación se enriqueció con los estrenos de Escuela normal (2012) Celina Murga y La toma (2013) de Sandra Gugliotta, mientras que en el campo de la ficción pueden destacarse obra como La mirada invisible (2010) de Diego Lerman, basada en la novela Ciencias morales de Martín Kohan y, más recientemente, La patota (2015) de Santiago Mitre (la película previa de este director, El estudiante, se enfocaba en el mundo universitario).

Para este análisis decidimos trabajar con La educación prohibida porque fue el documental sobre educación de mayor impacto que se haya estrenado en los últimos años -solo en Youtube acumulaba más de 15 millones de vistas- ${ }^{4}$, mientras que Después de Sarmiento fue elegido porque constituye el representante más reciente de este subgénero temático, a la vez que plantea un marcado contraste -en el plano de la forma y el contenido- con la otra película elegida.

La educación prohibida no fue producida ni circuló de la manera habitual para el cine argentino. Es una realización estrictamente independiente, hecha sin subsidios del INCAA, dirigida por Germán Doin y producida por Verónica Guzzo, con nada menos que 704 coproductores de diferentes países, quienes colaboraron con dinero o aportando su trabajo (música, animaciones, subtítulos, etcétera). Fue estrenada en Buenos Aires en el Paseo La Plaza en 2012. En paralelo se organizaron 150 proyecciones en 119 ciudades de 13 países: el equipo

\footnotetext{
${ }^{4}$ Consultado por última vez el 09/08/2019.
} 
Alfredo Dillon Entre la diversidad y el estereotipo: representaciones juveniles en dos documentales argentinos recientes

ofreció a quien quisiera la posibilidad de organizar una función; los interesados solo tuvieron que descargarse la película de Internet. El mismo día del estreno, el documental fue liberado en Youtube: acumuló un millón de reproducciones en la primera semana (una cifra impensable para cualquier película argentina), solo en esa plataforma. Son números excepcionales para un proyecto autogestionado, financiado de manera colectiva y conducido por un grupo de cuatro jóvenes de entre 21 y 24 años.

Es un documental expositivo (Julianne Burton, 1990) con una clara intención activista. Está construido a partir de una voz over y entrevistas, complementadas con animaciones que ilustran el discurso verbal y una ficcionalización, todo dividido en 10 capítulos a lo largo de casi 2 horas y media de película. Allí se recogen las miradas y experiencias de representantes de distintas pedagogías alternativas que cuestionan las estructuras y métodos de la escuela. Se presentan experiencias educativas innovadoras de Argentina, Chile, Colombia, Ecuador, España, Perú y Uruguay -el director viajó a todos estos países para hacer las entrevistas-, con el objetivo de mostrar otras maneras posibles de pensar el proceso educativo. Como cuenta con una licencia abierta de Creative Commons, los responsables de la película alientan a descargarla, copiarla, reeditarla y redistribuirla gratuitamente. La cultura se protege compartiéndola es el lema que abre y cierra el documental.

Después de Sarmiento fue dirigido por Francisco Márquez y filmado con un subsidio del INCAA: la "quinta vía", una línea de apoyo exclusiva para documentales que no exige que los directores tengan antecedentes, lo que se traduce en el fomento de óperas primas. Luego de circular por varios festivales, fue estrenado en el Espacio INCAA Gaumont, la sala porteña dedicada exclusivamente al cine nacional. Con horarios muy limitados, la película tuvo unos 8000 espectadores a lo largo de 3 semanas de proyección, y luego siguió circulando por institutos de formación docente y universidades (Entrevista a Francisco Márquez, 2015).

Este documental es eminentemente narrativo; tiene un formato observacional (Burton, 1990) sin entrevistas ni voz en off, en la línea de las estéticas del cine directo y el cinéma vérité (María Luisa Ortega, 2005). Se narran dos conflictos principales: las diferencias entre los alumnos del turno mañana y el turno tarde en torno a la conformación del centro de estudiantes, y los múltiples desajustes entre la institución escolar y los intereses de los chicos. Fue filmado en el Colegio Domingo F. Sarmiento, una escuela pública de la Ciudad de Buenos Aires ubicada muy cerca de la Villa 31 de Retiro, que reúne a alumnos de distintos sectores sociales. La cámara logró volverse invisible gracias a que el director trabajó durante un año en la escuela en el marco de un proyecto pedagógico que buscaba promover el uso del lenguaje audiovisual en articulación con las materias tradicionales. A la hora de pensar el proyecto de su película, el propio Márquez la planteó en contraposición con La educación prohibida: 
Alfredo Dillon Entre la diversidad y el estereotipo: representaciones juveniles en dos documentales argentinos recientes

Nosotros la tomamos como anti referencia. En varios sentidos. El primero es que la película se posiciona en el lugar de revelar una verdad. Más allá de eso, lo que más nos molestaba de la película era que se plantea un modelo de educación muy progresista, muy libertario, pero sumamente elitista. (Entrevista a Francisco Márquez, 2015)

A continuación exploramos qué representaciones sobre los adolescentes emergen en estas dos obras. Aunque el foco de la indagación esté en las representaciones juveniles que circulan en estas películas, cabe aclarar que ninguna de las dos se presenta a sí misma como un reflejo generacional o una película sobre los adolescentes, sino que estos ingresan a las obras en tanto estudiantes, puesto que el eje temático de ambos documentales es la educación. De todas maneras, la problematización de la institución escolar resulta inseparable de la reflexión sobre las características, necesidades y deseos de los adolescentes actuales, quienes constituyen el centro del proceso educativo.

\section{La educación prohibida: adolescentes hablados}

El documental dirigido por Germán Doin está dedicado a los niños y jóvenes que quieren crecer en libertad. Esta primera apelación a los jóvenes explicita cuál es el espectador modelo (Umberto Eco, 2000) construido por la película, y además prefigura una de las ideas centrales que gravitan a lo largo de la obra: la aspiración a la libertad como una de las características definitorias de los jóvenes.

La película está estructurada a partir de entrevistas a pedagogos, psicólogos y referentes de diversas pedagogías alternativas (Montessori, logosofía, educación holística, Waldorf, etcétera), pero no incluye ninguna entrevista a estudiantes. En La educación prohibida, el punto de vista de los adolescentes es asumido - de manera paternalista- por la enunciación de la propia película, que se erige en defensora de los intereses de niños y jóvenes por medio de la voz over del propio director. Se trata de una voz sin fisuras, portadora del saber y responsable de revelar una verdad oculta. Tiene a su cargo el hilo conductor del documental: anticipa y resume los aportes de los entrevistados, orienta las interpretaciones, pero en ningún momento los contradice; en ese sentido, los testimonios y la voz over funcionan de modo redundante. Tampoco exhibe el proceso de investigación que ha dado pie al guión de la película: el saber se presenta como acabado y objetivo, pese a que al comienzo del documental se incluye una aclaración que plantea que ninguna afirmación de la película debe considerarse concluyente $o$ absoluta.

Aunque no se los entrevista ni se da voz a adolescentes reales, estos sí aparecen como protagonistas de la ficcionalización que atraviesa la película y le aporta una mínima trama narrativa. El conflicto es el siguiente: dos alumnos del último año de la secundaria 
Alfredo Dillon Entre la diversidad y el estereotipo: representaciones juveniles en dos documentales argentinos recientes

(interpretados por los actores Santiago Magariños y Amira Adre) han escrito un discurso muy crítico acerca de lo que el colegio les deja después de 12 años de escolarización (en ese discurso aparece la frase La educación está prohibida). La directora del colegio -construida de manera caricaturesca, como una mujer rígida y autoritaria- se opone a que los chicos lean ese texto en el acto de fin de año. Las escenas que hacen avanzar este conflicto se intercalan con las entrevistas y la voz over a lo largo de una estructura de diez capítulos, y apuntan a aligerar la pesada carga expositiva que la película busca transmitir en sus 145 minutos.

En estos segmentos ficcionales, los personajes adolescentes carecen de rasgos locales, más allá del acento argentino. Ni su vestimenta (sin marcas reconocibles) ni su lenguaje (ajeno a cualquier cronolecto o sociolecto específico) ni la escuela a la que asisten pueden ser referidos a un contexto social determinado: estos jóvenes funcionan como adolescentes "universales". La construcción desprovista de rasgos particulares obedece, por un lado, a la pretensión internacional de la película, que fue concebida para un público más amplio que el argentino desde su origen. Por otra parte, la configuración de una escuela y unos adolescentes arquetípicos, esenciales, es coherente con el planteo central que la película formula por medio de sus testimonios y su enunciador: allí se cuestiona a la escuela en términos abstractos y generales, omitiendo cualquier vínculo entre las escuelas (en plural) y los diversos contextos sociales y políticos en que estas operas.

Esta construcción de jóvenes arquetípicos, abstractos y descontextualizados, contrasta con la célebre fórmula de Pierre Bourdieu (1990) según la cual «la juventud no es más que una palabra». Para Bourdieu, la juventud constituye una categoría construida y dinámica, que adquiere diferentes características a lo largo del tiempo y el espacio. No es posible, entonces, pensar en una sola forma de ser joven: la experiencia juvenil está mediada por diversos factores, como el género, el nivel socioeconómico, la extracción urbana o rural, y la pertenencia a instituciones educativas, laborales o religiosas. Esa diversidad está ausente de La educación prohibida, que sacrifica el realismo de sus representaciones juveniles en pos de un alcance explicativo lo más amplio posible.

El documental apela a la ficcionalización para ilustrar muchos de los argumentos sostenidos por los entrevistados y el narrador. En estas secuencias, los adolescentes son presentados como fundamentalmente pasivos. Con excepción de los dos protagonistas que se rebelan contra la institución escolar, el resto de los jóvenes que aparecen en la película se configuran como víctimas de la escuela, objetos modelados a la medida de esta institución, considerada aquí como represiva, homogeneizadora y absurda.

Otro rasgo de los adolescentes que aparece con recurrencia en la película es el deseo de reconocimiento, en línea con los aportes de Erikson (1980), para quien la tarea central del 
Alfredo Dillon Entre la diversidad y el estereotipo: representaciones juveniles en dos documentales argentinos recientes

sujeto en la adolescencia es la búsqueda y afirmación de la identidad individual. En este sentido pueden interpretarse las animaciones en las que los estudiantes aparecen reclamando No soy un número (en rechazo a las calificaciones), así como las secuencias en las que se muestra a los adolescentes etiquetados por los docentes, sosteniendo carteles que dicen Soy un 7 , Soy regular, Soy mediocre. Las calificaciones se oponen así a la singularidad de cada joven, y se presentan como un mecanismo estigmatizante.

La idea de la trayectoria escolar como un proceso de etiquetado y homogeneización de los estudiantes reaparece en otra de las animaciones que compara al dispositivo escolar con una cadena de montaje, evocando una secuencia emblemática de la película The Wall (1982). Este concepto se subraya en otra escena que presenta a los estudiantes vestidos de gris (igualados por el uniforme), con la mirada fija en el piso del aula, moviéndose todos al unísono de manera sincronizada, como en una coreografía sin sentido.

La obsolescencia del formato escolar hace emerger una de las representaciones juveniles más frecuentes en los medios audiovisuales: la figura del adolescente apático y desinteresado. Vemos entonces en distintas escenas a los alumnos en clase distraídos, jugando a las cartas, aburridos, durmiendo sobre el banco, las chicas pintándose las uñas. De todos modos, los argumentos de la película justifican esa abulia, que sería estrictamente responsabilidad de una escuela anticuada y excesivamente rígida.

El discurso de varios de los entrevistados presenta la adolescencia como una etapa en la que ya se ha dilapidado buena parte del potencial propio de la infancia, en gran medida por culpa de la escuela. En la película predomina una concepción idealizada del niño como un buen salvaje rousseauniano: la bondad y los talentos del niño se ven corrompidos por la institución escolar. La película sostiene una posición espontaneísta (Juan Carlos Tedesco, 1993, p. 269) según la cual el proceso de aprendizaje se confunde con el de socialización y el desarrollo del individuo consiste en la libre expresión de las potencialidades que el niño trae consigo por naturaleza. Como explica Tedesco, conviven en esta perspectiva la defensa de la libertad individual y la afirmación de un determinismo natural.

La película insiste constantemente en el desajuste entre la institución escolar y las necesidades e intereses de los adolescentes. De igual manera sostiene que los jóvenes también son incomprendidos en sus familias: cuando la ficcionalización incorpora los personajes de los padres de los alumnos, estos se muestran indiferentes hacia sus hijos y las demandas de ellos. ¿No querés recibirte, tener un título, una profesión, ser alguien en la vida?, plantea el padre de una de las chicas; ella responde, de modo algo previsible: Yo ya soy alguien en la vida. Para estos padres, la iniciativa de los chicos de criticar a la escuela en su discurso de fin de año es una estupidez. Los adultos resultan así caricaturizados como insensibles y desinteresados en 
Alfredo Dillon Entre la diversidad y el estereotipo: representaciones juveniles en dos documentales argentinos recientes

sus propios hijos, incapaces de empatizar con ellos. En este sentido, del discurso de la película se desprende la existencia de una brecha generacional prácticamente insalvable.

Esa brecha es ilustrada en una de las metáforas finales del documental. Una de las últimas escenas muestra a un joven que va cargando sobre sí mismo múltiples mochilas y valijas, símbolos evidentes de las demandas ajenas. Reaparece aquí la idea del adolescente pasivo, objeto y rehén de la escuela y la familia, instituciones gobernadas por los adultos. Poco después de esta secuencia, el narrador apela directamente al espectador: Liberemos nuestras expectativas, dice, mientras el joven se deshace de las mochilas que lo obligaban a cargar con las demandas de las instituciones sociales. En este gesto, que la película muestra a modo de exhortación explícita, las expectativas de los adultos son presentadas como lo opuesto de la posibilidad de los adolescentes de elegir: un obstáculo para los organismos destinados a autodesarrollarse libremente.

Frente a esta mirada sobre las instituciones de socialización, no puede sorprender que la ficción incluida dentro del documental esté protagonizada por un par de adolescentes rebeldes y contestatarios, los autores del discurso crítico sobre la escuela (con quienes la película se identifica). La imagen del joven rebelde puede reconocerse como una de las representaciones juveniles más cristalizadas en los discursos mediáticos y artísticos. ${ }^{5}$ La voz over llega a afirmar que la rebeldía y la necesidad de transformar la realidad son las características esenciales de los jóvenes, según la concepción espontaneísta y determinista del narrador. ${ }^{6}$

El documental concluye con el manifiesto de estos alumnos disconformes, a quienes les prohíben leer el discurso en el colegio, y en consecuencia deciden grabarlo y subir el video a Youtube (en un gesto que vuelve a subrayar la identificación entre los "jóvenes rebeldes" y los autores de la película). La crítica a la escuela se vuelve entonces una declaración pública; los chicos dicen basta (Basta de decidir por nosotros, basta de calificarnos, basta de imponernos. Ni las ciencias, ni los exámenes, ni los títulos nos definen). Esta primera persona del plural se confunde con la que enseguida utilizará la voz over (Esta es nuestra propuesta...); de esta manera, el enunciador se identifica con los adolescentes y se asume como vocero de ellos. No

\footnotetext{
${ }^{5}$ Hay una larga tradición en este sentido, que va desde James Dean, Los 400 golpes y La naranja mecánica en el cine hasta personajes literarios emblemáticos como Emil Sinclair en Demian de Hermann Hesse o Holden Caulfield en El guardián entre el centeno, de J.D. Salinger.

${ }^{6}$ A tres años del estreno de la película, el director relativiza algunas de estas posiciones: «Hay ideas a las que les dimos espacio pero ahora pensamos que quizás no está tan bueno que estén dando vueltas, como ciertas ideas biologicistas, o que pueden dar pie a lecturas biologicistas» (Entrevista a Germán Doin, 2015).
} 
Alfredo Dillon Entre la diversidad y el estereotipo: representaciones juveniles en dos documentales argentinos recientes

estaría de más decir, en consecuencia, que La educación prohibida se reivindica a sí misma como una película adolescente.

Después de Sarmiento: los rostros del desconcierto

En este documental, filmado en el Colegio Sarmiento, una escuela secundaria pública del barrio porteño de Recoleta, las voces y los rostros de los adolescentes predominan sobre los de los adultos. La cámara está constantemente a la altura de los chicos, registrando sus reacciones durante las clases, las discusiones fuera del horario escolar, las conversaciones en el recreo. Tal vez lo más interesante de Después de Sarmiento sean esos primeros planos que logran expresar un estado de ánimo, una intimidad; que alcanzan para individualizar sujetos aunque nunca lleguemos a saber sus nombres ni sus historias.

Estos adolescentes portan las huellas de un espacio y un tiempo específicos, de una cultura juvenil particular: proliferan los auriculares, las gorras con visera, las capuchas, las zapatillas vistosas, los celulares. Son adolescentes reales y no reconstruidos para una ficcionalización: no hay aquí arquetipos ni pretensiones de universalismo; de todos modos, probablemente estos personajes sean reconocibles para cualquier espectador extranjero. Los emblemas de la cultura juvenil son resaltados deliberadamente en la película, y hasta resultan problematizados, como en la escena en la que los alumnos discuten con la rectora, Roxana, si el uso de la gorra en clase constituye o no una falta de respeto.

En la escena que abre la película se pone en juego otro elemento que forma parte de los gustos y los consumos culturales de estos adolescentes de clase baja y media baja: la cumbia. Vemos un acto escolar, los abanderados en el escenario, suena el Himno a Sarmiento en la versión contemporánea de Kevin Johansen y Pablo Lescano. Los alumnos se sacan fotos con los celulares, algunos permanecen con los auriculares puestos en la fila... hasta que el himno vira definitivamente hacia la cumbia, y ese ritmo familiar los hace reaccionar, avivar las miradas, intercambiar sonrisas cómplices. Sin la mediación del lenguaje verbal, esta primera secuencia deja planteada una hipótesis acerca de lo que sucede en la escuela: hay un divorcio entre la institución y la cultura de quienes transitan por ella; si esa brecha se saldara, probablemente sucederían otras cosas entre esos muros.

No hay aquí, entonces, pretensiones de representar a los adolescentes, sino en todo caso estos adolescentes, en tanto que alumnos de una escuela pública porteña ubicada en la frontera entre la ciudad y la villa. Por otra parte, sí resulta posible leer esta escuela de manera metonímica, como representante de muchas otras: el efecto se logra porque la cámara nunca sale de la escuela, no muestra la fachada ni los exteriores. Ahí radica precisamente el interés 
Alfredo Dillon Entre la diversidad y el estereotipo: representaciones juveniles en dos documentales argentinos recientes

del documental: más allá de la literalidad, los conflictos del Colegio Sarmiento parecen ser en buena medida los de las escuelas públicas en la Argentina de la segunda década del siglo XXI. El universo retratado por el documental permite atisbar la necesidad de hablar de juventudes y adolescencias en plural: se señalan las diferencias entre los alumnos de clase media (los que asisten al turno mañana) y los de clase baja (que integran mayormente el turno tarde). Esta distinción es también territorial: de las intervenciones de alumnos y docentes se desprende que los chicos de la mañana viven mayormente en los barrios de la Capital, mientras que a la tarde asisten más chicos de la cercana Villa 31 de Retiro. Son dos colegios distintos, plantea una alumna, repitiendo un lugar común instalado en esa comunidad educativa. La brecha y los recelos mutuos entre estos dos grupos de jóvenes emergen en las escenas en las que se reúnen a discutir la posibilidad de conformar un único centro de estudiantes que congregue a los chicos de los dos turnos.

A la mañana vienen menos chicos de la villa, se supone, dicen. A la mañana el chico está más escolarizado que el de la tarde, plantea en una reunión la directora, Roxana, que constituye una de las protagonistas de la película y que -en contraste total con el personaje de la directora de La educación prohibida- ejerce su tarea docente de manera innovadora y flexible, abriendo constantemente la participación de los alumnos y promoviendo su reflexión crítica. La diversidad de los adolescentes se complejiza además con la que exhiben los acentos de los chicos, de distintas procedencias: algunos son originarios de provincias como Jujuy y Formosa; también hay otros que llegaron a Buenos Aires desde países limítrofes.

El discurso de los personajes también traza fronteras simbólicas -superpuestas con fronteras territoriales- entre la escuela pública y las escuelas privadas vecinas, a las que supuestamente asisten todos rubios de ojos celestes, según describe una alumna que siente la desconfianza de esos chicos hacia el alumno del Sarmiento (morochito, viserita...). Los personajes de la película marcan constantemente lo que Mario Margulis (1999) denomina la «racialización de las relaciones de clase», señalando la relevancia del factor racial -racista- en la constitución de las clases sociales en la Argentina.

El documental también insinúa la fragmentación del sistema educativo: en las escuelas argentinas no conviven sectores acomodados y sectores pobres, sino que cada uno asiste a distintos tipos de colegio (Cecilia Veleda, 2012). Los discursos de los personajes incluso trazan diferencias entre las escuelas públicas marginales (como el Sarmiento) y las escuelas públicas de élite a las que aún asiste la clase media (como el Colegio Nacional de Buenos Aires o el Carlos Pellegrini), pese al proceso sostenido de migración de estos sectores al sistema de educación privada en las últimas décadas. 
Alfredo Dillon Entre la diversidad y el estereotipo: representaciones juveniles en dos documentales argentinos recientes

Uno de los conflictos centrales del documental es el desencuentro entre la institución escolar y los intereses de los alumnos, evidente en cada una de las escenas de clase, incluso las de la profesora más entusiasta, Roxana, que intenta acercarse a los estudiantes de manera personalizada y con una propuesta pedagógica que los involucre activamente. Pese a los esfuerzos de algunos docentes -los que no se han dado por vencidos-, hay alumnos que desprecian la escuela y dicen no encontrarle sentido. La verdad es que el colegio en este momento no deja nada, plantea una chica en una reunión con la directora y los docentes. El desajuste y la disconformidad se expresan en las palabras de los chicos, en sus acciones (no llevan los útiles al colegio, no responden cuando un profesor les pregunta algo, no hacen la tarea), pero sobre todo en sus rostros, a veces cansados, a veces serios o desconfiados, con la mirada fija en el piso, casi siempre ajenos a lo que el docente propone.

La ineficacia pedagógica de la escuela -subrayada también en La educación prohibida- se plantea por ejemplo a partir del olvido inmediato en que caen los aprendizajes que tienen lugar allí. ¿Qué es lo que pasa que terminan quinto año y se van sin nada en la mochila, o con muy poco?, se pregunta Roxana. En otra escena, la directora les pregunta a los chicos cuánto tiempo les dura lo que estudian para los exámenes. Un día, responde uno. Esa media hora de prueba, contesta otra.

La necesidad de revisar el formato escolar queda planteada de manera clara y da pie a las escenas de discusión sobre la reforma de la escuela secundaria. En este punto, el foco está puesto en la inclusión, un concepto central del debate educativo en la última década, en particular a partir de la obligatoriedad de la secundaria. Los directivos se plantean cómo lograr una inclusión real: ¿Cuál es la verdadera inclusión escolar? ¿Que los chicos estén adentro de la escuela como sea, no importa qué estén haciendo?, se preguntan.

El problema remite a lo que Rossana Reguillo (2012) y otros críticos denominan inclusión desigual: los jóvenes incluidos de manera desigual «se ven obligados a ocupar posiciones que, si bien los mantienen en un 'adentro' social, no son más que espacios precarizados que se alimentan de la fantasía de la pertenencia» (p. 139). En otras palabras: estos adolescentes vulnerables ahora están escolarizados -muchos de ellos son la primera generación de sus familias en acceder a la escuela, según explica Roxana en el acto de fin de año-, pero el hecho de asistir a la escuela no es sinónimo de recibir una buena educación ni, mucho menos, un signo de igualdad de oportunidades.

\section{Conclusiones}

La educación prohibida y Después de Sarmiento coinciden en algunos cuestionamientos hacia la escuela, en particular los relacionados con su impotencia pedagógica, sus dificultades para 
Alfredo Dillon Entre la diversidad y el estereotipo: representaciones juveniles en dos documentales argentinos recientes

generar aprendizajes significativos e interesar a los adolescentes actuales. Pero aunque las dos puedan definirse como documentales sobre educación, probablemente sean más las diferencias que los puntos en común.

Desde el punto de vista formal, se encuentran en las antípodas. Después de Sarmiento elige una forma más abierta, observacional, en la que la trama narrativa se construye a partir del montaje. El espectador es aquí un testigo de lo que sucede en las aulas, la cámara se inmiscuye y registra lo que sucede, limitando su intervención al mínimo posible. En La educación prohibida, en cambio, la voz over y los entrevistados aportan sentidos cerrados, plantean preguntas pero también ofrecen las respuestas. La película se sostiene sobre la conducción de un narrador paternalista y omnisciente, que siempre sabe más que los sujetos sobre quienes habla -los profesores, los niños, los adolescentes, los padres- e intenta comprenderlos a todos. La voz over se identifica con la autoridad y el saber: es portadora de un conocimiento que debe ser transmitido para sembrar conciencia en los destinatarios.

Del contraste entre ambas películas surge la pregunta acerca de qué relevancia tiene (o debiera tener) el punto de vista de los jóvenes en un documental sobre la escuela. Después de Sarmiento responde esa pregunta dando prioridad a las voces y rostros de los adolescentes, eligiéndolos como protagonistas, mostrándolos en su apatía pero también en sus intentos de organizarse colectivamente. En La educación prohibida, en cambio, esas voces y rostros están ausentes de los segmentos propiamente documentales, y los adolescentes emergen apenas como categorías abstractas o como estereotipos en las secuencias ficcionalizadas, cuya verosimilitud no resulta del todo lograda. El narrador y los entrevistados hablan sobre los adolescentes reales, pero estos no toman la palabra.

Las decisiones formales se traducen, a su vez, en representaciones muy distintas sobre los adolescentes. En La educación prohibida predominan los estereotipos, entre ellos la directora autoritaria, el docente comprensivo y solo dos clases de adolescentes: por un lado los pasivos, víctimas del poder disciplinario y homogeneizador de la escuela, y por el otro los rebeldes, quienes se atreven a cuestionar la institución escolar y terminan haciendo públicas sus críticas por medio de Youtube, en un gesto análogo al que realiza el propio equipo productor del documental. En Después de Sarmiento aparecen los matices: no hay un arquetipo de adolescente sino que se visibilizan las diferencias de clase social y procedencia geográfica. Los adolescentes aparecen aquí en su contexto y con las marcas propias de su cultura, incluyendo los códigos de vestimenta, giros lingüísticos y gustos musicales.

Si bien cada documental tiene objetivos distintos - uno se presenta como activista; el otro solo intenta plantear algunas preguntas en relación con la escuela-, y en ese sentido son esperables las diferencias de abordaje, lo cierto es que la construcción un adolescente esencial 
en La educación prohibida invisibiliza las desigualdades sociales que Después de Sarmiento sí evidencia. Mientras la primera se sustenta en una argumentación de tipo filosófico e intenta construir un alegato de alcance universal, la segunda, en cambio, se inscribe en una matriz antropológica: cuenta una historia en una escuela -sin desconocer que esa historia es representativa de muchas otras y puede leerse de manera metonímica, pero tampoco aspirando a presentar la escuela y los adolescentes-. Al comparar ambos documentales, se vuelve evidente que ninguna representación juvenil puede lograr verosimilitud si no inserta a esos jóvenes en su comunidad, es decir, si omite los contextos sociales en que esos jóvenes estudian, trabajan, crecen y viven.

\section{Referencias bibliográficas}

Bourdieu, P. (1990). La juventud no es más que una palabra. En Sociología y cultura (pp. 163174). México: Grijalbo.

Buckingham, D. (2008). Youth, Identity and Digital Media. Cambridge: MIT Press.

Burton, J. (1990). The Social Documentary in Latin America. Pittsburgh: University of Pittsburgh Press.

Cartoccio, E. (2010). Representaciones paternas en el Nuevo Cine Argentino. Ponencia presentada en el $2^{\circ}$ Congreso Internacional de la Asociación Argentina de Estudios de Cine y Audiovisual (ASAECA), Buenos Aires. Recuperado de www.asaeca.org/aactas/cartoccio eduardo.pdf

Chanan, M. (2007). El documental y el espacio público. En Català, Josep María y Cerdán, Josetxo (eds.) Después de lo real, Archivos de la Filmoteca, Vol. 1 (57-58). Valencia: Instituto Valenciano de Cinematografía, pp. 68-99.

Eco, U. (2000). El lector modelo. En Lector in fabula (pp. 73-95). Barcelona: Lumen.

Entrevista a Francisco Márquez, diciembre de 2015.

Entrevista a Germán Doin, diciembre de 2015.

Erikson, E. (1980). Identidad, juventud y crisis. México: Paidós.

Farhi, A. (2005). Una cuestión de representación. Los jóvenes en el cine argentino, 1983-1994. Buenos Aires: Libros del Rojas.

Goldstein, M. (2008). Jóvenes de película. La problemática juvenil en el cine argentino (19952001). Buenos Aires: Tercer Milenio.

Margulis, Mario; Urresti, Marcelo y otros (1999). La segregación negada. Cultura y discriminación social. Buenos Aires: Biblos. 
Meschengieser, S. y Lisica, F. (2004). Apuntes sobre la marginalidad y la apatía. Los jóvenes en el cine argentino de los 90. En Revista Chilena de Antropología Visual, № 4, Santiago, pp. 103-117.

Ortega, M. L. (2005). Documental, vanguardia y sociedad. Los límites de la experimentación. En Torreiro, Casimiro y Cerdán, Josetxo (eds.) Documental y vanguardia (pp. 185-217). Madrid: Cátedra.

Plantinga, C. (2011). Documental. En Cine Documental, № 3, Buenos Aires. Recuperado de $<$ www.revista.cinedocumental.com.ar/3/traducciones.html>

Reguillo Cruz, R. (2012). Culturas juveniles. Formas políticas del desencanto, Buenos Aires: Siglo XXI.

Tedesco, J. C. (1993). Educación y sociedad en la Argentina (1880-1945). Buenos Aires: Solar.

Touraine, A. (2006). Un nuevo paradigma para comprender del mundo de hoy, Buenos Aires: Paidós.

Veleda, C. (2012). La segregación educativa. Entre la fragmentación de las clases medias y la regulación atomizada. Buenos Aires: Stella-La Crujía. 